\title{
Optimal Control and Bidding Strategy of Virtual Power Plant with Renewable Generation
}

\author{
Yuchang Kang, Kwoklun Lo \\ University of Strathclyde, Glasgow, UK \\ Email: yuchang.kang@strath.ac.uk
}

How to cite this paper: Kang, Y.C. and Lo, K. (2016) Optimal Control and Bidding Strategy of Virtual Power Plant with Renewable Generation. World Journal of Engineering and Technology, 4, 27-34.

http://dx.doi.org/10.4236/wjet.2016.43D004

Received: July 13, 2016

Accepted: October 13, 2016

Published: October 20, 2016

\begin{abstract}
A Virtual Power Plant (VPP), aggregating the capacities of distributed energy resources (DER) as a single profile, provides presence of DERs in the electricity market. In this paper, a stochastic bidding model is proposed for the VPP to optimise the bids in the day-ahead and balancing market, with the objective to maximise its expected economic profit. The performance of proposed strategy has been assessed in a modified commercial VPP (CVPP) system with wind generation installed, and also the results are compared with the ones achieved from other commonly-used strategies to verify its feasibility.
\end{abstract}

\section{Keywords}

Virtual Power Plant, Electricity Market, Distributed Energy Resources

\section{Introduction}

During the recent decades, the environmental concerns, increasing energy demand and economic consideration have led to increased renewable energy resources (RES) penetration worldwide, which results in a significant growth of renewable Distributed Generators (DG) in several power systems [1]. Renewable DGs may have the opportunities to participate in energy markets, however, due to the stochastic characteristics of RES, individual DGs is highly risky to meet the accepted schedules of the power system, which makes the market participate impossible.

In literature, researchers have adopted a variety of ways so far in order to optimize the performance of DGs in the existing power systems within the concept of smart grid. Among all, demand response (DR) and energy storage system (ESS) have proven to be the most significant factor for the deployment of the smart grid, since the challenges of the large-scale RES penetration can be relieved and the system reliability can be im- 
proved [2]. The installation of advanced metering infrastructure, which can deliver real-time electricity prices to consumers, can improve the efficiency for integration of intermittent resources into the electricity grid [3]. On the other hand, the quick response characteristic of ESS makes it as a valuable regulation resource to balance the negative effects of the RES [4].

The VPP concept, where generation of individual renewable DGs are aggregated into a single operating profile, is supposed to be an efficient way toward the successful coupling of RES with DR and ESS. In European project FENIX [5], the VPP concept is defined as "an aggregation of the capacity of many diverse distributed energy resource; it creates a single operating profile from a composite of the parameters characterizing each DER and can incorporate the impact of the network on aggregated DER output." The aggregated DERs of a VPP can include renewable DGs and conventional power plants as well as DR and ESS schemes. Two types of VPP are described: the Commercial VPP (CVPP) and the Technical VPP (TVPP). The main difference between CVPP and TVPP is that CVPP does not consider the impact of the network, while TVPP takes into account the real-time influence of the local network on the portfolio.

Since a VPP can participate in the electricity market, it is essential that the owner of the VPP is able to determine the optimal control and bidding strategy of the portfolio with the aim to minimize its cost (or maximize its profit). Although the conduct is rich in optimization problems dealing with control and bidding strategy of a conventional power plant [6]-[8], there are a few researches addressing the same problem for a renewable power plant, or a VPP so far. The stochastic characteristics of RES makes it a challenging problem to reduce the market cost for VPP. Reference shows that scheduling dispatchable generators [9] [10] and deploying elastic demand [11] [12] can help reduce the imbalancing power caused by renewable uncertainties. From above, one promising way is to curtail some of the renewable generation to reduce the expensive imbalance cost [13] [14]. A recent work [15] has proven that in balancing market, however, it does not consider the optimization in day-ahead market. The research conduct shown in [16] includes the scheduling of power generated from renewable DGs, while it does not consider the balancing market since RES is usually used as a reserve capacity.

In the above framework, this paper proposes a novel control and bidding strategy for VPP in both day-ahead and balancing market. The problem is formed as a stochastic bi-level optimization model of a CVPP, which comprises distributed generation (wind farm) and inelastic consumers (residential and/or commercial load) and aims at the minimization of its cost (or maximization of its profit). This model offers the VPP owner determination of the optimal renewable power usage and day-ahead bids for each time unit of the coming day. The uncertainty lies in the DER production is covered by applying the coordinated strategy, which limits the renewable generation as a function of demand. Comparison is made with two other commonly used control strategy: (1) the greedy strategy, which fully utilizes the renewable power; (2) the absolute strategy [17], which limits the renewable generation by a predefined value. Moreo- 
ver, the market costs under VPP and non-VPP frameworks are investigated and compared.

The main contribution of this paper are as follow. 1) A novel control strategy on renewable generation is introduced in order to reduce the market cost of VPP; 2) A stochastic bi-level optimization model is formulated and solved for the minimization of the VPP's market cost.

The rest of the paper is organized as follows. Section 2 presents the VPP configuration and control strategy. Section 3 formulates the optimization problem. Section 4 provides numerical results from the application. And finally section 5 concludes the paper.

\section{Model and Control Strategy Description}

\subsection{Model Description}

In the proposed model, it is assumed that all DG units included in the VPP have granted to the VPP owner, where owner can receive the forecasted information and has a direct control on each unit. As a result, the owner submits offer/bids for generation or consumption based on the whole profile's operational constraints and estimation. To simplify the model, all wind farm of the VPP are aggregated into a single wind farm, and all consumers are combined into a single load entity. Since in the VPP framework individual generator and demand unit does not present a complex constraint, the simplification is acceptable and benefits for reducing the computational tractability. Figure 1 shows the CVPP portfolio structure and power flow transactions. Where $\mathrm{P}_{\mathrm{t}}{ }^{\mathrm{W}}$ is the total wind generation information, $\mathrm{P}_{\mathrm{t}}^{\mathrm{W}, \mathrm{a}}$ is the actual wind generation after control strategy, $\mathrm{P}_{\mathrm{t}}^{\mathrm{L}}$ is the total load demand information, and $\mathrm{P}_{\mathrm{t}}^{\mathrm{Net}}$ is the power exchange between the VPP and the external grid.

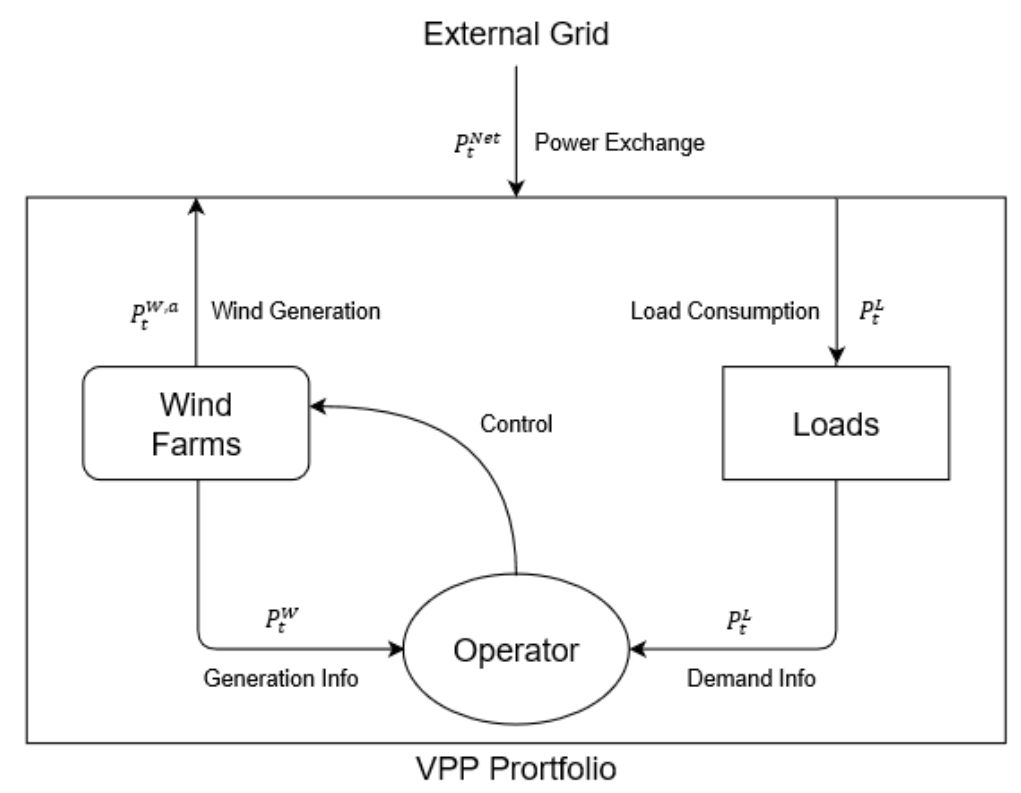

Figure 1. CVPP Protfolio structure and power flow transactions. 


\subsection{Control Strategy}

As described in Section 1, In order to reduce the imbalance cost of the VPP system, control strategies are applied to curtail some wind generation. Since the ESS is not considered in the model, the unused wind generation is spilled. Therefore, three control strategies are introduced in the following.

1) Coordinated Strategy: This strategy limits the ratio of wind generation to demand at time $\mathrm{t}$ by a predefined upper limit $\delta_{\mathrm{t}}$, i.e.

$$
P_{t}^{W, a}=\min \left(P_{t}^{W}, \delta_{t} P_{t}^{L}\right), \delta_{t} \in[0, A]
$$

where $\mathrm{A}$ is the upper bound constant of the ratio between wind generation and load demand. It means if the wind generation is above the predefined limit, the spilled power will be curtailed, otherwise if the wind generation is lower than the constant, it will be fully utilized. This strategy shows a characteristic of DR since it benefits from the relationship between generation and load. The wind generation information $\mathrm{P}_{t}{ }^{\mathrm{W}}$ can be identified from historical data.

2) Greedy Strategy: This strategy always fully utilizes wind generation at time t, where

$$
P_{t}^{W, a}=P_{t}^{W}
$$

3) Absolute Strategy: This strategy limits the wind generation itself at time t by a predefined upper bound constant ${ }_{\mathrm{c}}$, i.e.

$$
P_{t}^{W, a}=\min \left(P_{t}^{W}, \varepsilon_{t} P_{t}^{W, C}\right), \varepsilon_{t} \in[0,1]
$$

where $\mathrm{P}_{\mathrm{t}}{ }^{\mathrm{W}, \mathrm{C}}$ is the maximum capacity of the total wind generators. The only difference between coordinated strategy and absolute strategy is that absolute strategy has no consideration about the demand side.

\section{Market Formulation}

The market model described below is based on the Nord pool. Power contract of a minimum of one-hour duration are traded in the day-ahead market, then any imbalancing issues are paid as an upward regulation (increased generation or reduced consumption) or downward regulation (decreased generation or increased consumption) price in the balancing market [18].

In the model, assuming the VPP participate into the market as a price taker. It submits the hourly bid $B_{t}$ for the next day, then any imbalancing penalty $C_{t}^{p}$ between $B_{t}$ and $\mathrm{P}_{t}{ }^{N e t}$ at time $t$ is settled in the balancing market. The market cost of VPP $\mathrm{C}_{t}{ }^{\mathrm{VPP}}$ can be formulated as

$$
C_{t}^{V P P}=\lambda_{t}^{s} B_{t}+C_{t}^{P}
$$

where $\lambda_{t}^{s}$ is the spot price at time t. The imbalancing penalty $\mathrm{C}_{\mathrm{t}}^{\mathrm{p}}$ can be defined as a function of the deviation, $\Delta_{t}$, between the power exchange and bid, and the upward regulation price $\lambda^{+}$or downward regulation price $\lambda^{-}$, 


$$
\begin{gathered}
C_{t}^{P}= \begin{cases}\lambda^{+} \Delta_{t}, & \Delta_{t} \geq 0 \\
\lambda^{-} \Delta_{t}, & \Delta_{t}<0\end{cases} \\
\lambda_{t}^{+}=\left(1+\alpha_{t}\right) \lambda_{t}^{s}, \lambda_{t}^{-}=\left(1-\beta_{t}\right) \lambda_{t}^{s}
\end{gathered}
$$

where $\alpha_{t}$ and $\beta_{t}$ are the differences between the spot price and the upward/downward regulation prices.

The stochastic characteristics of market price can be formulated as a random vector $\gamma_{t}$.i.e.

$$
\gamma_{t}=\left[\lambda_{t}^{s}, \alpha_{t}, \beta_{t}\right]
$$

where $\lambda_{t}^{s}, \alpha_{t}, \beta_{t}$ are independent random variables.

As the objective of the VPP is to minimize the total cost, it is necessary to make the optimal bids in the market. In the above framework, the problem can be formulated as a stochastic bi-level optimization problem, i.e.

$$
\min _{\delta_{t}} \min _{B_{t}} E_{\gamma_{t}} F\left(\delta_{t}, B_{t}, \gamma_{t}\right)
$$

where objective function

$$
F\left(\delta_{t}, B_{t}, \gamma_{t}\right)=\lambda_{t}^{s} \mathrm{E}\left(P_{t}^{N e t}\right)+\alpha_{t} \lambda_{t}^{s} \int_{B_{t}}^{\infty}\left(x-B_{t}\right) f_{P_{t}^{N e t}}(x) d x+\beta_{t} \lambda_{t}^{s} \int_{-P_{t}^{W, C}}^{B_{t}}\left(B_{t}-x\right) f_{P_{t}^{N e t}}(x) d x
$$

where $\mathrm{F}\left(P_{t}^{\text {Net }}\right)$ is the probability density function of $P_{t}^{\text {Net }}$.

\section{Case Study}

The proposed control and bidding strategy has been tested for a CVPP portfolio including wind farms and load at a total capacity of $30 \mathrm{MW}$, and it is considered to participate in the electricity market under Nord Pool system, with a time unit of 1 hour.

The forecast wind generation and demand data are obtained from the historical database by Elia [19], and all data are scaled down to meet the required 30MW install capacity. The historical data of market system including spot, upward/downward prices are gathered from the Nord Pool [20]. Other parameters are defined in Table 1.

The result of three control strategies: the coordinated strategy $(C)$, the greedy strategy (G) and the absolute strategy (A), are proceed in the case. For each strategy, the optimization problem is solved and results are summarized in Table 2. It can be seen that by applying both $\mathrm{C}$ and $\mathrm{A}$, the total cost of the VPP is lower than fully wind power utilized strategy, G.

To compare the three strategies in detail, the cost differences between the $\mathrm{C} / \mathrm{A}$ and $\mathrm{G}$ in each hour is plotted in Figure 2. It can be seen that both $\mathrm{C}$ and A save money in the case study. Moreover, the strategy $\mathrm{C}$ performs almost 3 - 5 times better than $\mathrm{A}$, which

Table 1. Parameters of case study.

\begin{tabular}{cccc}
\hline Type & $\mathrm{A}$ & $\alpha_{t}$ & $\beta_{t}$ \\
\hline Value & 3 & $0.1-0.7$ & $0.7-1.4$ \\
\hline
\end{tabular}




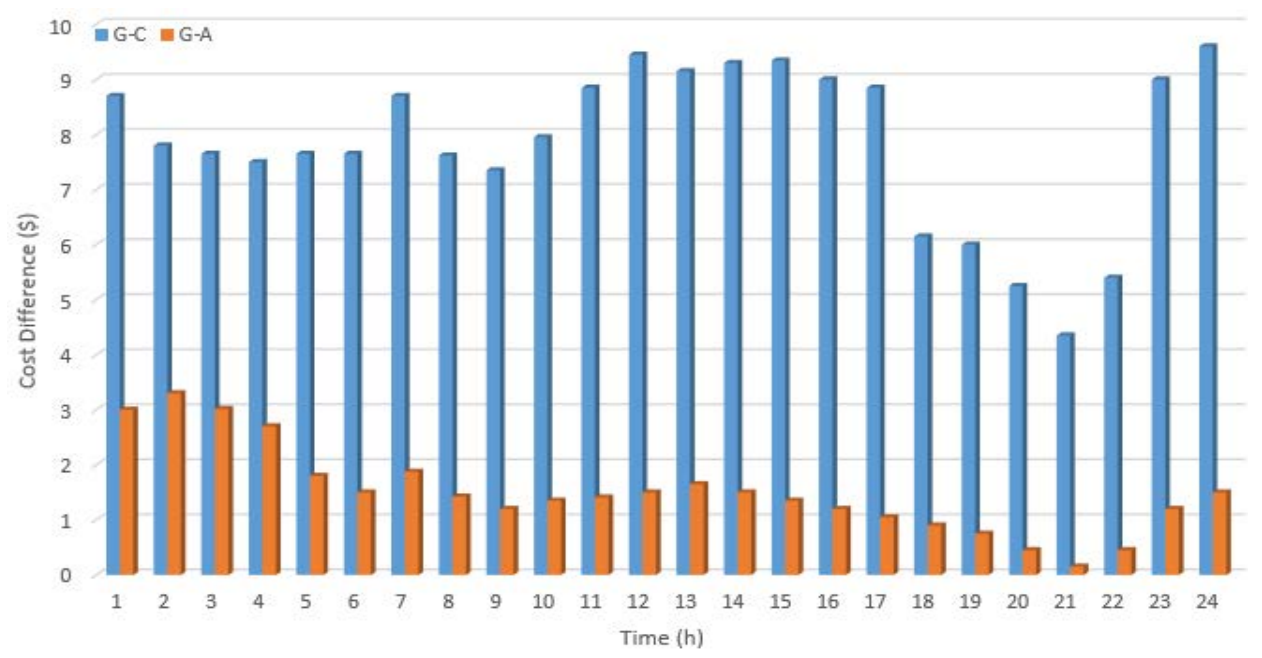

Figure 2. Cost difference between C/A and G for each hour.

Table 2. VPP total cost for three control strategies.

\begin{tabular}{ccc}
\hline Strategy & Bids $(\mathrm{MW})$ & Total Cost $(\$)$ \\
\hline G & 153.4 & $11,780.5$ \\
A & 158.1 & $11,748.4$ \\
C & 168.6 & $11,595.3$ \\
\hline
\end{tabular}

makes it a better control strategy. These results show that by applying suitable control strategy, the VPP owner could benefit for low market cost. What's more, the effect shown in the coordinated strategy presents the priority of the DR, which is an important advantage of the VPP concept.

A comparison of both VPP and non-VPP framework is also presented in the case study. In the same wind farm and loading conditions, participants in the market submit their bids individually in the non-VPP framework. As a result shown in Figure 3, under non-VPP model, the market cost is significant larger than those under VPP framework with three types of control strategies. It also demonstrates that coordinated strategy is the best control strategy for the given VPP framework.

\section{Conclusions}

This paper presents a novel control strategy for CVPP aggregated with RES, and a stochastic bi-level optimization model for the development of optimal bidding is created. Under these framework, the effect of the proposed control strategy is proven: the coordinated strategy, showing the principle of DR, saves more market cost for the CVPP system. The priority of VPP portfolio as a solution for Renewable DG management is also evaluated.

The proposed model can also be extended by adding ESS into the VPP portfolio as a future work, this technology combined with the control strategies will be evaluated. Based on that, it is necessary to extend the research to the aspect of TVPP, which considered the real-time influence of the local network. 


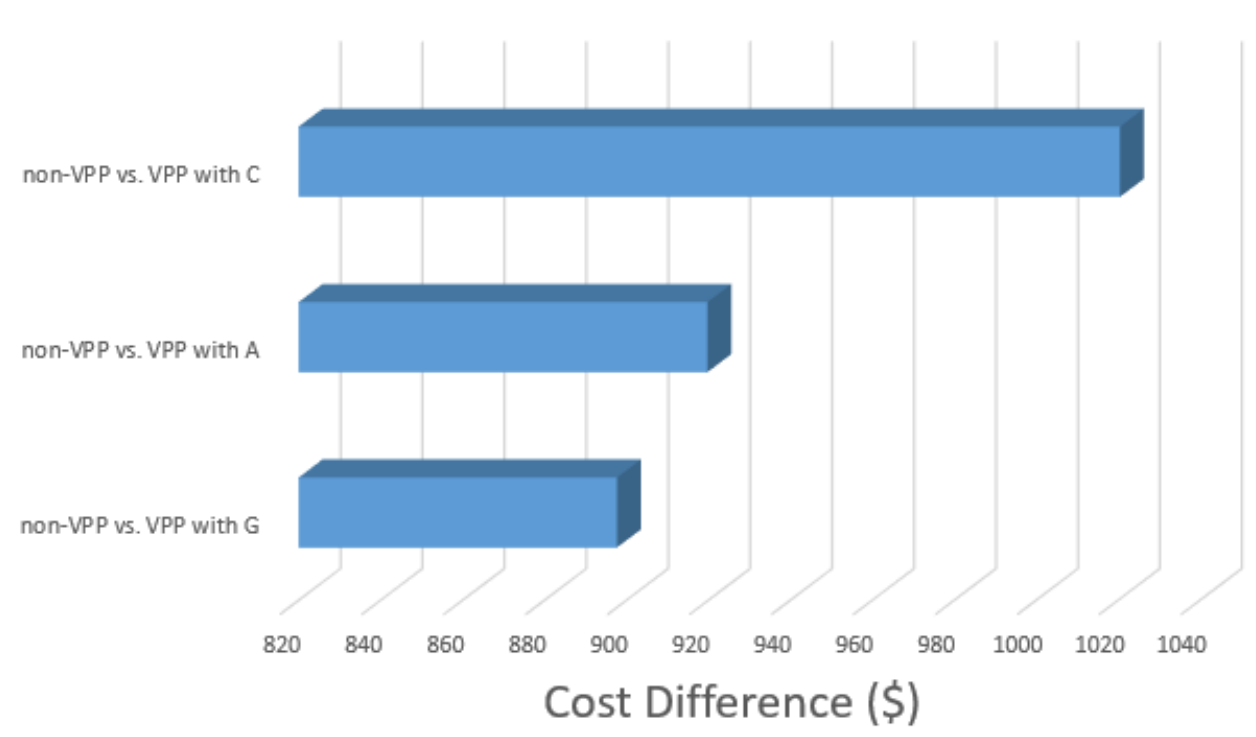

Figure 3. Cost difference between VPP and non-VPP framework.

\section{Acknowledgements}

Y. Kang thanks to Prof. Kwoklun Lo for supervising the research project. I would also thank to my parents, who gives me fully support during my study.

\section{References}

[1] Renewables 2014 Global Status Report. Renewable Energy Policy Network for the 21st Century (REN21), Paris, Tech. Rep. GSR2014, 2013.

[2] Atzeni, I., Ordóñez, L.G., Scutari, G., Palomar, D.P. and Fonollosa, J.R. (2013) Demand-Side Management via Distributed Energy Generation and Storage Optimization. IEEE Trans. Smart Grid, 4, 866-876. http://dx.doi.org/10.1109/TSG.2012.2206060

[3] Farhangi, H. (2010) The Path of the Smart Grid. IEEE Power Energy Mag., 8, 18-28. http://dx.doi.org/10.1109/MPE.2009.934876

[4] Lee, D., Kim, J. and Baldick, R. (2013) Stochastic Optimal Control of the Storage System to Limit Ramp Rates of Wind Power Output. IEEE Trans. Smart Grid, 4, 2256-2265. http://dx.doi.org/10.1109/TSG.2013.2285524

[5] Pudjianto, D., Ramsay, C., Strbac, G. and Durstewitz, M. (2008) The Virtual Power Plant: Enabling Integration of Distributed Generation and Demand. FENIX Bull, 2.

http://fenix.iwes.fraunhofer.de/docs/public/2008_02_01_FENIX_bulletin_No_2.pdf

[6] Simoglou, C.K., Biskas, P.N. and Bakirtzis, A.G. (2010) Optimal Selfscheduling of a Thermal Producer in Short-Term Electricity Markets by MILP. IEEE Trans. Power Syst., 25, 1965-1977. http://dx.doi.org/10.1109/TPWRS.2010.2050011

[7] Ruiz, C. and Conejo, A.J. (2009) Pool Strategy of a Producer with Endogenous Formation of Locational Marginal Prices. IEEE Trans. Power Syst., 24, 1855-1866. http://dx.doi.org/10.1109/TPWRS.2009.2030378

[8] Kardakos, E.G., Simoglou, C.K. and Bakirtzis, A.G. (2014) Optimal Bidding Strategy in Transmission-Constrained Electricity Markets. Elect. Power Syst. Res., 109, 141-149. http://dx.doi.org/10.1016/j.epsr.2013.12.014

[9] Varkani, A.K., Daraeepour, A. and Monsef, H. (2011) A New Self-Scheduling Strategy for 
Integrated Operation of Wind and Pumped-Storage Power Plants in Power Markets. Appl. Energy, 88, 5002-5012. http://dx.doi.org/10.1016/j.apenergy.2011.06.043

[10] Al-Awami, A.T. and El-Sharkawi, M.A. Coordinated Trading of Wind and Thermal Energy. IEEE Trans. Sustain. Energy, 2, 277-287. http://dx.doi.org/10.1109/TSTE.2011.2111467

[11] Tascikaraoglu, A., Erdinc, O., Uzunoglu, M. and Karakas, A. (2014) An Adaptive Load Dispatching and Forecasting Strategy for a Virtual Power Plant including Renewable Energy Conversion Units. Appl. Energy, 119, 445-453. http://dx.doi.org/10.1016/j.apenergy.2014.01.020

[12] Pandzic, H., Kuzle, I. and Capuder, T. (2013) Virtual Power Plant Mid-Term Dispatch Optimization. Appl. Energy, 101, 134-141. http://dx.doi.org/10.1016/j.apenergy.2012.05.039

[13] Bitar, E.Y., Rajagopal, R., Khargonekar, P.P., Poolla, K. and Varaiya, P. (2012) Bringing Wind Energy to Market. IEEE Trans. Power Syst., 27, 1225-1235. http://dx.doi.org/10.1109/TPWRS.2012.2183395

[14] Bouffard, F. and Galiana, F.D. (2008) Stochastic Security for Operations Planning with Significant Wind Power Generation. Proc. IEEE Power Energy Soc. Gen. Meeting Convers. Del. Elect. Energy 21 st Century, 1-11. http://dx.doi.org/10.1109/pes.2008.4596307

[15] Guo, Y., Gong, Y., Fang, Y. and Khargonekar, P.P. (2014) Stochastic Minimization of Imbalance Cost for a Virtual Power Plant in Electricity Markets. Proc. IEEE PES Innov. Smart Grid Technol. Conf. (ISGT), 1-5. http://dx.doi.org/10.1109/isgt.2014.6816372

[16] Peik-Herfeh, M., Seifi, H. and Sheikh-El-Eslami, M. (2013) Decision Making of a Virtual Power Plant under Uncertainties for Bidding in a Day-Ahead Market Using Point Estimate Method. Int. J. Elect. Power Energy Syst., 44, 88-98. http://dx.doi.org/10.1016/j.ijepes.2012.07.016

[17] Ackermann, T., et al. (2012) Wind Power in Power Systems. 2nd Edition, Wiley, Hoboken. http://dx.doi.org/10.1002/9781119941842

[18] N. P. ASA (2004) The Nordic Power Market. http://www.fer.unizg.hr/_download/repository/Nord\%20Pool\%20-\%20The\%20Nordic\%20 Power\%20Market.pdf

[19] Elia (2016) Belgium's Electricity Transmission System Operator. http://www.elia.be/en/grid-data/power-generation/wind-powerhttp://www.elia.be/en/griddata/Load-and-Load-Forecasts/total-load\#01

[20] The Nord Pool. http://www.nordpoolspot.com/ 
Submit or recommend next manuscript to SCIRP and we will provide best service for you:

Accepting pre-submission inquiries through Email, Facebook, LinkedIn, Twitter, etc. A wide selection of journals (inclusive of 9 subjects, more than 200 journals)

Providing 24-hour high-quality service

User-friendly online submission system

Fair and swift peer-review system

Efficient typesetting and proofreading procedure

Display of the result of downloads and visits, as well as the number of cited articles

Maximum dissemination of your research work

Submit your manuscript at: http://papersubmission.scirp.org/

Orcontactwjet@scirp.org 